\title{
High Sensitivity EPMA: Past, Present and Future
}

John J. Donovan

CAMCOR, University of Oregon, Eugene, OR, 97403

Investigators have endeavored to improve elemental detection sensitivity for electron probe micro analysis (EPMA) since the first metallurgical measurements made by Castaing. These improvements have been made over many decades through a combination of hardware and software developments. These include more stable electron guns, low noise gas flow detectors, high speed counting electronics, large area analyzing crystals along with more sophisticated methods for fitting the x-ray continuum and interpolating the actual background intensity under the peak of interest.

The bane of high sensitivity microanalysis has always been the appropriate characterization of the x-ray continuum intensity and shape. This effort also includes attempts to reduce the contribution of the $\mathrm{x}$-ray continuum relative to the characteristic signal with wavelength dispersive spectrometry (WDS) in order to improve the signal to noise ratio by dispersing all $\mathrm{x}$ ray wavelengths except that of the line of interest. Of course even with WDS instrumentation the background under the peak remains and must be determined by off-peak measurements or by various background modeling methods and eventually subtracted.

Results published in the 1970s showed that WDS EPMA was already able to obtain detection limits on the order of hundreds of PPM in a number of common silicates and oxides, while energy dispersive spectrometer (EDS) detectors at that time were limited to minimum detection limits in the thousands of PPM. This all changed in the early 2000s when SDD devices could handle $\mathrm{x}$-ray count rates similar to EPMA and were no longer beam current limited. These new high throughput SDD EDS devices raised the bar for WDS sensitivity, in situations where the lower spectral resolution of the EDS is not problematic, particularly when the trace element identities are completely unknown. Recent measurements at NIST [1] show that modern, large area SDD devices can attain 99\% confidence at the 180 PPM level for P in a lead silicate glass (NIST SRM K-523) with somewhat higher values for higher Z elements. In the last decade [2] [3], high sensitivity WDS EPMA measurements of Ti in quartz showed detection limits of 10 to 20 PPM using long count times, however systematic errors from continuum artifacts limited further improvement. More recent work by Donovan, et al., 2011 has demonstrated a 99\% confidence t-test detection limit of 2 to 3 PPM for Ti in quartz when utilizing multiple spectrometer intensity measurements aggregated with a new "blank" correction for improved accuracy to correct for subtle analyzing crystal diffraction effects. This latest WDS result directly competes with Laser Ablation Inductively Coupled Mass Spectrometry (LAICPMS) for sensitivity but with superior spatial resolution. 


\section{References:}

[1] Newbury, D. and Ritchie, N., "Measuring Trace Level Constituents with SEM/SDD-EDS", Microscopy and Microanalysis Conference Proceedings, 2009

[2] Rusk, B., Reed, M., Dilles, J., and Kent, A. Intensity of quartz cathodoluminescence and trace element content of quartz from the porphyry copper deposit in Butte, Montana. American Mineralogist, 1006, v. 91 , p. $1300-1312$

[3] Wark, D.A., and Watson, B.E., 2006, TitaniQ: A titanium in quartz geothermometer. Contributions to Mineralogy and Petrology, 2006, v. 152, p. 743-754

[4] Goldstein, J. I., Newbury, D. E., Echlin, P., Joy, D.C., Lyman, C. E., Lifshin, E., Sawyer, L. C., and Michael, J.R., Scanning Electron Microscopy and X-Ray Microanalysis: A text for biologists, materials scientists, and geologists ( $2^{\text {nd }}$ Edition), Plenum Press, 1992, p. 436

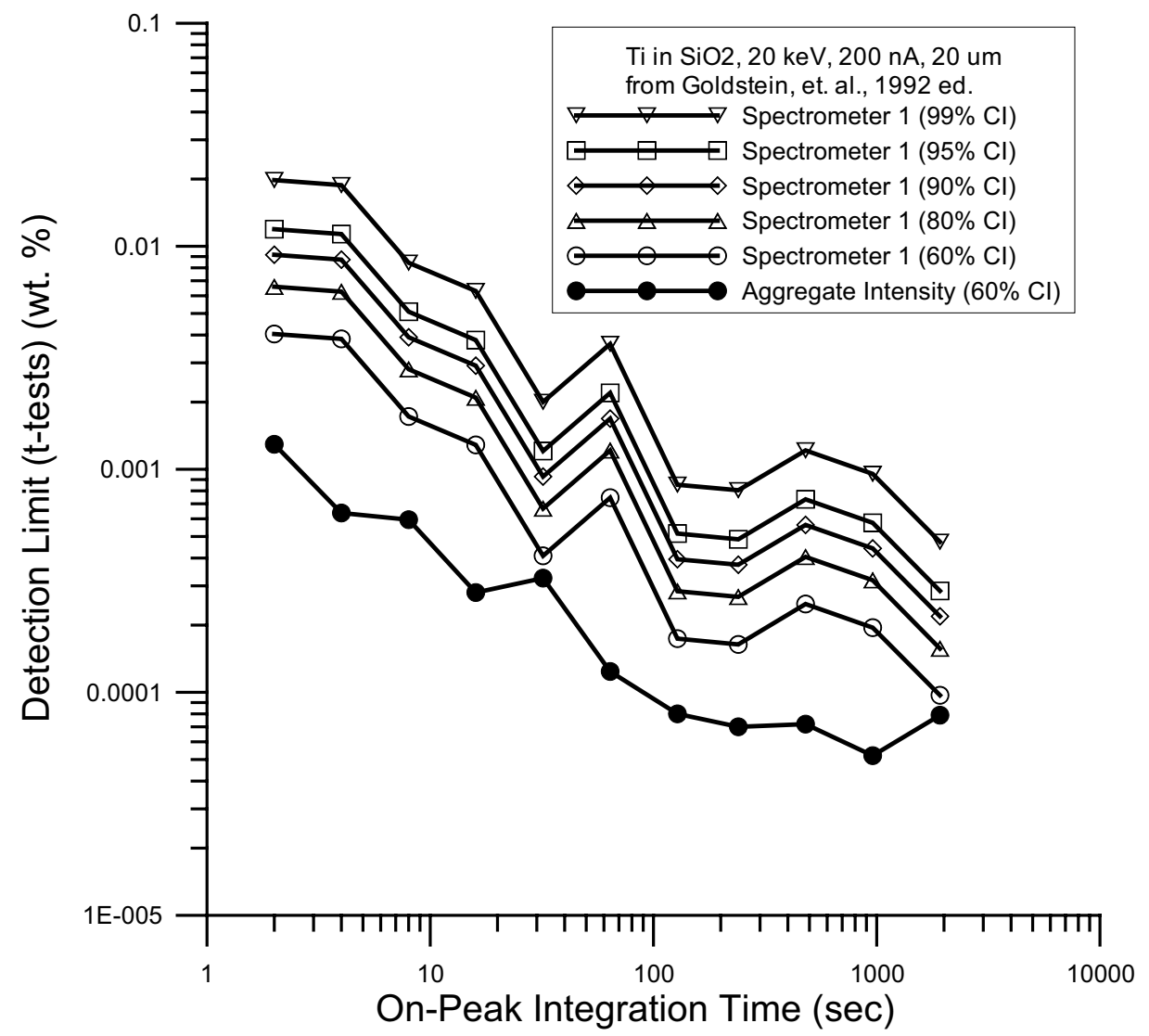

Figure 1. Comparison of individual spectrometer sensitivity t-tests, 60 to $99 \%$ confidence intervals $(\mathrm{CI})$, along with the software enabled aggregate intensity option at $60 \% \mathrm{CI}$ as a function of counting time as measured on pure $\mathrm{SiO}_{2}$ (1.42 PPM Ti by ICP-MS). T-test sensitivity was calculated using the method of Goldstein, et al.[4]. Data was acquired on a Cameca SX100 with 5 spectrometers. For counting times exceeding 100 seconds, the $60 \%$ CI t-test for the blank corrected and aggregate intensities were at or below the $1 \mathrm{ppm}$ level. 